\title{
Erratum to: Greater occipital nerve block in chronic migraine
}

\author{
Maria Gabriella Saracco $\cdot$ W. Valfrè • \\ M. Cavallini $\cdot$ M. Aguggia
}

Published online: 3 May 2011

(C) Springer-Verlag 2011

\section{Erratum to: Neurol Sci (2010) 31(Suppl 1):S179-S180 DOI 10.1007/s10072-010-0320-7}

This article has been retracted on request of the editor because it reproduced literally significant sections of another article: "Greater occipital nerve block using local anaesthetics alone or with triamcinolone for transformed migraine: a randomised comparative study" (A. Ashkenazi, R. Matro, J.W. Shaw, M.A. Abbas, S.D. Silberstein. J Neurol Neurosurg Psychiatry 2008; 79:415-417) that is not even quoted in the reference list.
Dr. Aguggia acknowledges full responsibility for this unfortunate accident, which he attributes to an unintentional mistake and not to an intentional plagiarism. Whichever was the mechanism, the result was a serious violation of the publishing rules and the Editor in Chief and the Publisher are deeply sorry for any inconvenience that this may have caused to the editorial and publishing staff of the Journal of Neurology, Neurosurgery \& Psychiatry and to the authors of the reproduced article.

The online version of the original article can be found under doi:10.1007/s10072-010-0320-7.

M. G. Saracco $(\bowtie) \cdot$ W. Valfrè · M. Cavallini - M. Aguggia Neurological Department, ASL AT-Asti,

Ospedale Cardinal Massaia, Via Conte Verde 125, Asti, Italy

e-mail: saraccomg@asl.at.it; sgabriella@aol.it 